\section{World Thrombosis Day — October 13, 2016}

October 13, 2016, is World Thrombosis Day. Deep vein thrombosis (DVT) and pulmonary embolism (PE) are together referred to as venous thromboembolism (VTE). A DVT is a blood clot that develops in the veins of the lower leg, thigh, pelvis, or arm; PE occurs when a portion of a DVT breaks off and travels through the bloodstream to the lungs.

VTE is an underdiagnosed and serious, but preventable, condition that affects up to 900,000 persons and is responsible for an estimated 60,000-100,000 deaths in the United States each year (1). Risk factors for VTE include injury to a vein, slow blood flow, increased estrogen levels, certain chronic medical illnesses, and family history, as well as presence of a catheter in a central vein, advanced age, obesity, inherited clotting disorders, and previous VTE. Approximately one third of persons who have a VTE will have a recurrence within 10 years (1).

The theme of this year's World Thrombosis Day is health care-associated VTE (HA-VTE). Approximately half of all VTEs are related to a recent hospitalization or surgical procedure; and most of these VTEs do not occur until after hospital discharge $(2,3)$. As much as $70 \%$ of cases of HA-VTE are preventable with appropriate use of anticoagulants or compression stockings (4-G), yet fewer than half of hospitalized patients at risk for HA-VTE receive these measures ( 7 ).

CDC is working to increase HA-VTE awareness and prevention. CDC, in partnership with the National Blood Clot Alliance, recently launched the Stop the Clot, Spread the Word campaign, which provides resources to reduce HA-VTE for patients and providers; awareness and prevention measures include risk assessment tools, educational materials, videos, and infographics. Readers can learn more about HA-VTE on the Stop the Clot website (https://www.stoptheclot.org/ spreadtheword/), and can access resources by visiting the CDC Venous Thromboembolism website (http://www.cdc. gov/ncbddd/dvt/index.html).

\section{References}

1. Beckman MG, Hooper WC, Critchley SE, Ortel TL. Venous thromboembolism: a public health concern. Am J Prev Med 2010;38(Suppl):S495-501. http://dx.doi.org/10.1016/j.amepre.2009.12.017

2. Heit JA, Silverstein MD, Mohr DN, et al. The epidemiology of venous thromboembolism in the community. Thromb Haemost 2001;86:452-63.

3. Spencer FA, Emery C, Joffe SW, et al. Incidence rates, clinical profile, and outcomes of patients with venous thromboembolism. The Worcester VTE study. J Thromb Thrombolysis 2009;28:401-9. http://dx.doi. org/10.1007/s11239-009-0378-3

4. Zeidan AM, StreiffMB, Lau BD, et al. Impact of a venous thromboembolism prophylaxis "smart order set": improved compliance, fewer events. Am J Hematol 2013;88:545-9. http://dx.doi.org/10.1002/ajh.23450

5. Mitchell JD, Collen JF, Petteys S, Holley AB. A simple reminder system improves venous thromboembolism prophylaxis rates and reduces thrombotic events for hospitalized patients1. J Thromb Haemost 2012;10:236-43. http://dx.doi.org/10.1111/j.1538-7836.2011.04599.x

6. Lau BD, Haut ER. Practices to prevent venous thromboembolism: a brief review. BMJ Qual Saf 2014;23:187-95. http://dx.doi.org/10.1136/ bmjqs-2012-001782

7. Kahn SR, Morrison DR, Cohen JM, et al. Interventions for implementation of thromboprophylaxis in hospitalized medical and surgical patients at risk for venous thromboembolism. Cochrane Database Syst Rev 2013;7:CD008201. 